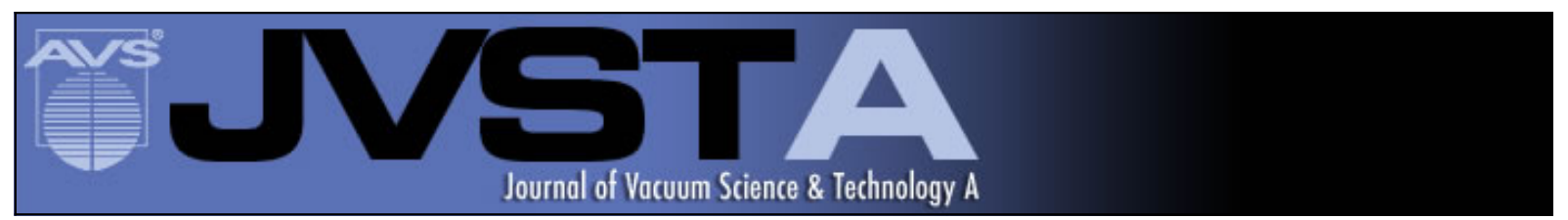

\title{
Graded silicon nitride films: Optics and passivation
}

Andrew Thomson, Yimao Wan, Niraj Lal, and Robert G. Elliman

Citation: Journal of Vacuum Science \& Technology A 33, 060610 (2015); doi: 10.1116/1.4935101

View online: http://dx.doi.org/10.1116/1.4935101

View Table of Contents: http://scitation.aip.org/content/avs/journal/jvsta/33/6?ver=pdfcov

Published by the AVS: Science \& Technology of Materials, Interfaces, and Processing

\section{Articles you may be interested in}

Tantalum oxide/silicon nitride: A negatively charged surface passivation stack for silicon solar cells Appl. Phys. Lett. 106, 201601 (2015); 10.1063/1.4921416

Characterisation and optimisation of PECVD SiNx as an antireflection coating and passivation layer for silicon solar cells

AlP Advances 3, 032113 (2013); 10.1063/1.4795108

Analysis of sub-stoichiometric hydrogenated silicon oxide films for surface passivation of crystalline silicon solar cells

J. Appl. Phys. 112, 054905 (2012); 10.1063/1.4749415

Characterization and comparison of silicon nitride films deposited using two novel processes

J. Vac. Sci. Technol. A 30, 021201 (2012); 10.1116/1.3687423

High-rate plasma-deposited Si O 2 films for surface passivation of crystalline silicon

J. Vac. Sci. Technol. A 24, 1823 (2006); 10.1116/1.2232580

\section{Instruments for Advanced Science} w www.HidenAnalytical.com E info@hiden.co.uk CLICK TO VIEW our product catalogue

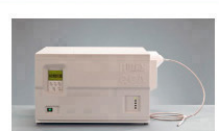

Gas Analysis

dynamic measurement of reaction gas streans cataysis and thermal analysis molecular beam studies

dissolved species probes

, fermentation environmental and ecological studes

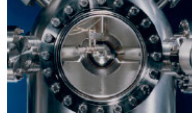

Surface Science

UHVTPD

SIMS emental imaging - surface mapping

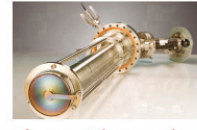

Plasma Diagnostics plasma source characterization etch and deposition process reaction , analysis of neutral and radical species

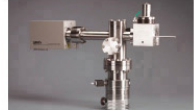

Vacuum Analysis partial pressure measurement and contro of process gases reactive sputter process contro vacuum diagnostics , 


\title{
Graded silicon nitride films: Optics and passivation
}

\author{
Andrew Thomson, ${ }^{\text {a) }}$ Yimao Wan, and Niraj Lal \\ The Research School of Engineering, The Australian National University, Canberra 0200, Australia \\ Robert G. Elliman \\ Department of Electronic Materials Engineering, The Australian National University, Canberra 0200, \\ Australia
}

(Received 2 August 2015; accepted 22 October 2015; published 6 November 2015)

\begin{abstract}
The authors describe a method for graded thin-film deposition requiring a single step that exploits the noninstantaneous replacement of reactant gases. They deposit the graded silicon-nitride films by plasma enhanced chemical vapor deposition. Channeling Rutherford backscattering measurements of the graded films find the N:Si ratio increases sixfold from the c-Si surface to air interfaces. The refractive index at the crystalline silicon/film interface was 2.96 reducing monotonically to 1.95 at the surface. The graded films achieve improved optics and surface passivation for silicon solar cells with measured surface recombination velocity of $3.9 \mathrm{~cm} / \mathrm{s}$. (C) 2015 American Vacuum Society.

[http://dx.doi.org/10.1116/1.4935101]
\end{abstract}

\section{INTRODUCTION}

Increasing the optical absorption and the emission of optoelectronic devices while achieving a good surface passivation is a pathway for improved performance. Silicon nitride $\left(\mathrm{SiN}_{\mathrm{x}}\right)$ films formed by plasma enhanced chemical vapor deposition (PECVD) are employed on c-Si devices as antireflection coatings (ARCs) and can provide excellent surface passivation. ${ }^{1,2} \mathrm{SiN}_{\mathrm{x}}$ films of moderate refractive index (approximately 2 at $633 \mathrm{~nm}$ ) are typically employed, in commercial c-Si cells encapsulated into modules, to increase transmission to the cell by mitigating reflection and parasitic optical absorption. Lauinger et al. has demonstrated that the passivation from conventional uniform- $\mathrm{SiN}_{\mathrm{x}}$ films monotonically decreases with decreasing silicon content. ${ }^{3}$ There is then a trade-off between achieving good passivation and absorption in the ARC, and hence transmission to the active cell region. ${ }^{3,4}$

Graded index ${ }^{5,6}$ and multilayer ${ }^{7-9}$ films have been touted as promising pathways toward improved device optics. Graded index films fabricated from $\mathrm{SiN}_{\mathrm{x}}$ can additionally lead to improved passivation due to the high interfacial silicon content ${ }^{3}$ and the redistribution of $\mathrm{SiN}_{\mathrm{x}}$ electronic defects ( $K$ - and $N$-center) away from the c-Si interface with $\mathrm{SiN}_{\mathrm{x}}$. This redistribution of the $K$ - and $N$-center defects has been found to reduce surface recombination. ${ }^{10,11}$ Previously, the formation of graded films has required continuous variation of deposition conditions during fabrication ${ }^{6}$ or an additional surface nitridation process. ${ }^{10} \mathrm{We}$ demonstrate here a method for depositing graded films in a single processing step that requires only a step change in the silane and ammonia gas flows at the time of plasma ignition. From three dimensional modeling of interdigitated back-contact (IBC) solar cells, ${ }^{12}$ coupled with simulations of the generation profile using OPAL2, ${ }^{13-15}$ we find that cells with graded layers acheive improved efficiency compared to cells with an $\mathrm{a}-\mathrm{Si} / \mathrm{SiN}_{\mathrm{x}}$ stack of uniform layers.
In this paper, we present two graded coatings in comparison to uniform films of stoichiometric $\mathrm{SiN}_{\mathrm{x}}$, silicon-rich $\mathrm{SiN}_{\mathrm{x}}$, and amorphous silicon. The deposition conditions are summarized in Table I. Rutherford-backscattering-channeling (RBS-C) analysis is used for determining the film stoichiometry, $X_{\mathrm{RBS}}$, as a function of depth. The $X_{\mathrm{RBS}}$ is correlated with the measurements of the refractive index $\left(n_{633}\right)$ as a function of depth determined by spectroscopic ellipsometry (SE). Chemical bonding in the films is also assessed by Fourier transform infrared spectroscopy (FTIR). Finally, the graded films are shown to result in an improved surface passivation of silicon when compared to uniform $\mathrm{SiN}_{\mathrm{x}}$ films.

\section{EXPERIMENT}

Two varieties of float zone silicon (100) were employed in this study. Passivation measurements used $1 \Omega \cdot \mathrm{cm}$ phosphorus-doped silicon wafers that were alkali etched prior to cleaning to remove surface damage, resulting in samples of $190 \pm 5 \mu \mathrm{m}$ thicknesses. SE, FTIR, and RBS-C measurements employed double-side polished silicon samples with a resistivity of $4400 \pm 900 \Omega \cdot \mathrm{cm}$. All samples were prepared according to the Radio Corporation of America procedure ${ }^{16}$ followed by deglazing in dilute hydrofluoric acid until hydrophobic. Postcleaning, the wafers were exposed to atmosphere for less than $2 \mathrm{~h}$ prior to coating. Silicon nitride films were deposited by direct-rf PECVD using an Oxford PlasmaLab 100 deposition system with $\mathrm{SiH}_{4}$ and $\mathrm{NH}_{3}$ source gases. The system had a loadlock to mitigate atmospheric contamination of the chamber and was preconditioned following the procedure described by Wan. ${ }^{17}$ Table I describes the recipes employed in this work. The recipes labeled U1, U2, and U3 correspond to uniform films of: silicon-rich $\mathrm{SiN}_{\mathrm{x}}$, stoichiometric $\mathrm{SiN}_{\mathrm{x}}$, and amorphous silicon, respectively. The recipes labeled G1 and G2 for the graded layers correspond to films with a moderate and a strong concentration gradients, respectively.

Prior to deposition, the PECVD chamber was evacuated to base pressure to remove residual atmospheric contamination. After the base pressure was reached, the deposition gases were introduced into the chamber. The pressure was then

${ }^{\text {a)} E l e c t r o n i c ~ m a i l: ~ a n d r e w . t h o m s o n @ a n u . e d u . a u ~}$ 
TABLE I. Deposition conditions and measured parameters for the five films deposited for this work. The preignition gas flows (Pre ign.) are the gas flows in the chamber during the gas and pressure stabilization prior to plasma ignition. The postignition gas flows (Post ign.) are the gas flows set points after plasma ignition. Also summarized are the film thickness and average refractive index from SE, the average $\mathrm{N}$ to $\mathrm{Si}$ ratio $\overline{X_{\mathrm{RBS}}}$, areal atomic density $\mathrm{t}_{\mathrm{RBS}}$ from RBS-C, the average atomic density $\rho_{\text {RBS }}$ from RBS-C, SE data from the FTIR bond densities, and the effective lifetime $\tau_{\text {eff }}$ at a $\Delta n$ of $1 \times 10^{15} \mathrm{~cm}^{-3}$.

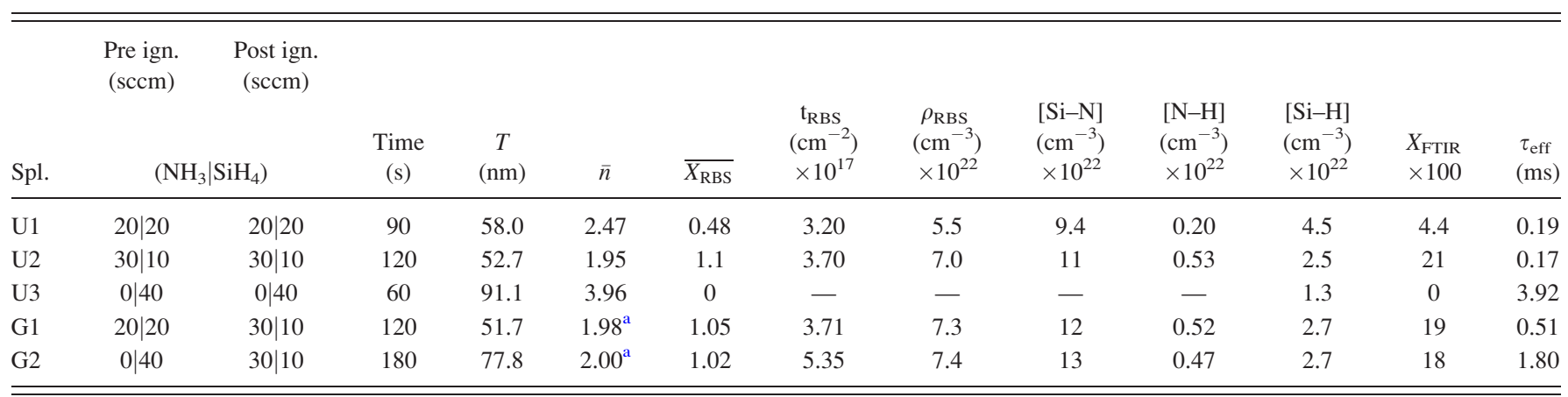

${ }^{\mathrm{a}}$ For the graded films, this is the refractive index determined by fitting a single layer model.

stabilized to a fixed processing pressure via a butterfly valve with a feedback controller. After stabilization at the processing pressure, the plasma was ignited. For the uniform films, the deposition gas flows were maintained at the same rates after ignition. For films G1 and G2, the gradients were achieved by altering the gas flows at plasma ignition, creating a transient shift in the ratio of silane to ammonia. The pre- and postignition gas flows are listed in Table I. All films were deposited at $400{ }^{\circ} \mathrm{C}$, with an $r f$ power of $50 \mathrm{~W}$ and with a deposition pressure of $650 \mathrm{mT}$.

\section{RESULTS AND DISCUSSION}

RBS-C measurements of the amorphous $\mathrm{SiN}_{\mathrm{x}}$ films were performed using $2.0 \mathrm{MeV} \mathrm{He}{ }^{+}$ions with a glancing-exit geometry. Incident ions were channeled along the [001]-axis of the crystalline Si substrate and detected at a scattering angle of $100^{\circ}$; the incident beam and detector angle are normal and $10^{\circ}$ to the sample surface, respectively. This setup reduced the scattering contribution from the substrate and helped delineation of the amorphous $\mathrm{SiN}_{\mathrm{x}}$ layer. ${ }^{18}$ Figure 1 shows the resulting RBS-C spectra together with the extracted $\mathrm{N}$ signals after the background subtraction. Qualitatively, the influence of the gradient recipe can be observed in the lower energy portion of the Si peak, where samples G1 and G2 have a decaying Si signal with increasing energy. The Si and N peaks were used to determine best-fit models for the sample structures using the RUMP code. ${ }^{19}$ From these measurements, it is found that samples $\mathrm{G} 1, \mathrm{G} 2$, and U2 have similar near-surface $\mathrm{SiN}_{\mathrm{x}}$ compositions, with an $\mathrm{N}$ to $\mathrm{Si}$ ratio $X_{\mathrm{RBS}}$ of $1.15,1.15$, and 1.18, respectively. Samples G1 and G2 have an additional Si-rich layer at the crystalline-Si/layer interface, and sample G2 has a graded composition that increases in Si content from the surface to the substrate interface. Sample U1 has a significantly higher Si content than the other samples, with an $X_{\mathrm{RBS}}$ of 0.51. The $X_{\mathrm{RBS}}$ used to model the RBS-C spectra for samples G1 and G2 in Fig. 1 are plotted in Fig. 2(b), where the $X_{\mathrm{RBS}}$ was calibrated by the SE measurements of thickness.

FTIR measurements were performed with a Bruker Vertex $80 \mathrm{~V}$ using an uncoated silicon piece as a background reference. The methodology described by Wan et al. ${ }^{4}$ was used to determine the concentration of the bond densities
$[\mathrm{Si}-\mathrm{N}],[\mathrm{N}-\mathrm{H}]$, and $[\mathrm{Si}-\mathrm{H}]$, summarized in Table I. The [Si-N] bond-density increases monotonically with increasing $\rho_{\text {RBS }}$, the average atomic density determined from RBS$\mathrm{C}$ and SE data. This indicates that for the graded layers, $[\mathrm{Si}-\mathrm{N}]$ is also indicative of density. ${ }^{20}$ Further, the atomic ratio of nitrogen to silicon measured by RBS-C (Ref. 20) $X_{\mathrm{RBS}}$, averaged for the graded films, is linearly related to the ratio of $[\mathrm{N}-\mathrm{H}]$ to $[\mathrm{Si}-\mathrm{H}], X_{\mathrm{FTIR}}$, measured by FTIR.

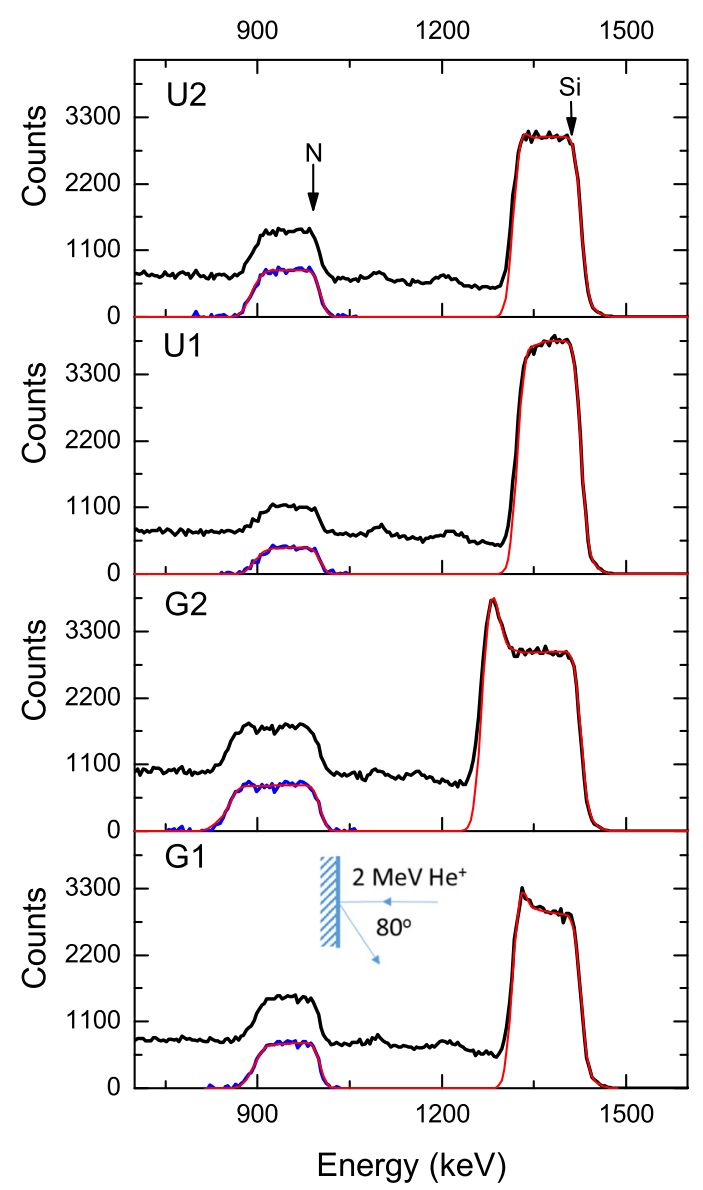

FIG. 1. (Color online) RBS-C spectra of samples G1, G2, U1, and U2 as labelled. Plots show RBS-C spectra in black, the extracted $\mathrm{N}$ peak with the grey (blue) line, and the extracted Si peak also in grey (red) as labelled. The fits were performed using the RUMP code (red) (Ref. 19). The inset in the lower panel shows the scattering geometry. 

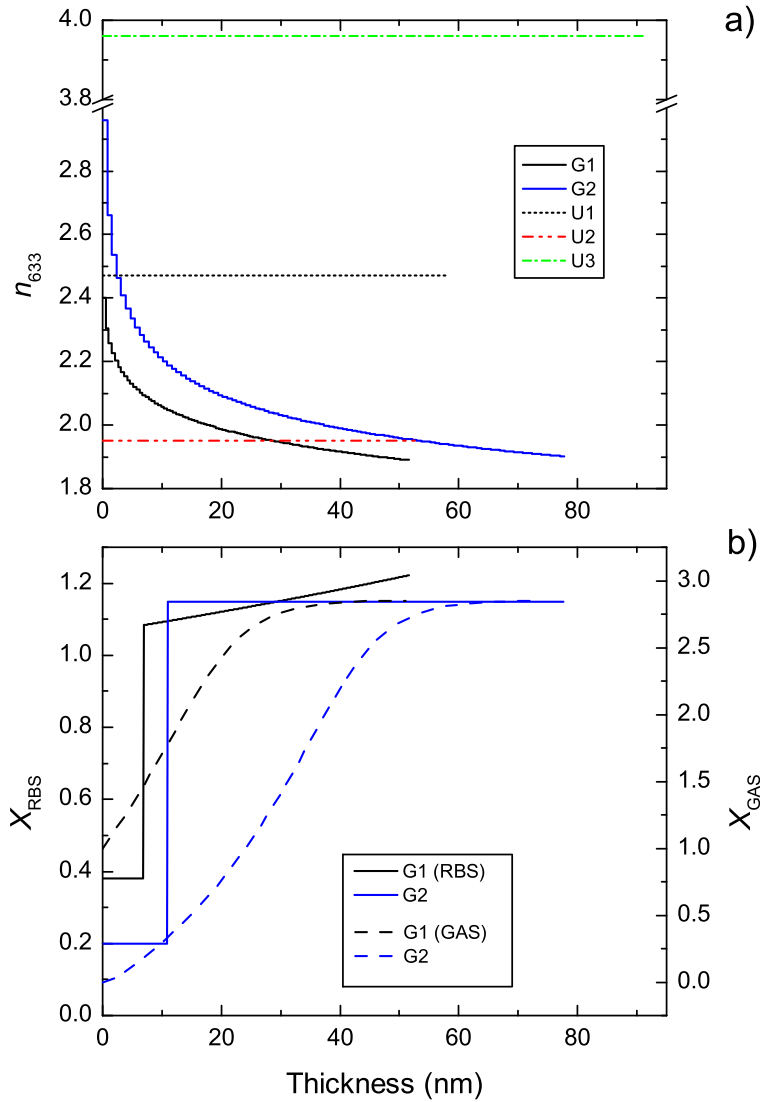

FIG. 2. (Color online) Graph (a) plots ellipsometry measured $n_{633}$ profile as a function of thickness from the top to the bottom of the samples listed in Table I. Note the break in the y-axis. Graph (b) plots $X_{\text {RBS }}$ (solid lines) vs calibrated film thickness (left $\mathrm{y}$-axis) and the modeled $X_{\text {gas }}$ (dashed lines) vs calibrated film thickness (right $y$-axis) for the samples U1 and $\mathrm{U} 2$.

SE measurements were made with a J. A. Woollam multiangle ellipsometry tool. All measurements were performed over wavelengths of $300-1500 \mathrm{~nm}$, at incident angles of $55^{\circ}$, $65^{\circ}$, and $75^{\circ}$. The measurements of $\mathrm{U} 1, \mathrm{U} 2$, and $\mathrm{U} 3$ were fitted with a two-layer model comprised of crystalline-Si (Ref. 21) and a thin-film simulated by the Tauc-Lorentz dispersion model. ${ }^{22}$ We summarize the results in Table I. Fitting of the graded films' SE measurements is achieved by using 100 subfilm slices to represent the changing refractive index through the film. Each slices' optical properties are fractional combinations of the top and bottom slices according to Bruggeman theory. ${ }^{23}$ The top and bottom slices are fitted by the Tauc-Lorentz dispersion model. ${ }^{22}$ The fractional composition of each slice is monotonically varied, resulting in the $n_{633}$ profiles as a function of depth plotted in Fig. 2(a), along with the measured refractive indices for the films U1, $\mathrm{U} 2$, and $\mathrm{U} 3$. We note that, when comparing the fitting error resulting from both the uniform two layer model and the sliced model to films G1 and G2, the use of the sliced model approximately halved the fitting error.

Figure 3 plots the effective surface recombination velocity, $S_{\text {eff }}$, of the symmetrically passivated samples. In this case, the $S_{\text {eff }}$ was determined from measurements of the effective lifetime $\tau_{\text {eff }}$, performed with a Sinton Instruments

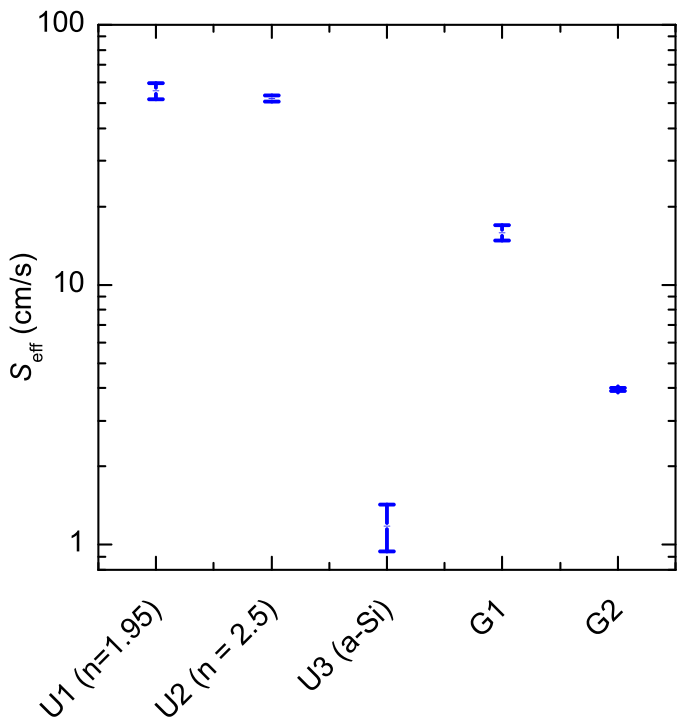

FIG. 3. (Color online) $S_{\text {eff }}$ of samples coated by the uniform films U1 to U3 and the graded films G1 and G2. The film deposition parameters are given in Table I.

WCT-120 with transient analysis. ${ }^{24}$ The measurements of $\tau_{\text {eff }}$ are summarized in Table I. The bulk lifetime was assumed to be limited by intrinsic recombination. ${ }^{25,26} \mathrm{We}$ find that both graded nitride films perform better than the uniform nitride films (U1 and U2). However, the best passivation is achieved by a-Si passivation (U3). Despite the fact that the deposition conditions were identical at the start of the process for $\mathrm{U} 3$ and $\mathrm{G} 2$, the $S_{\text {eff }}$ is increased from 1.2 to $3.9 \mathrm{~cm} / \mathrm{s}$. This reduction in passivation is likely caused by nitrogen insertion at the c-Si/film interface. Nitrogen insertion in a-Si and $\mathrm{SiN}_{\mathrm{x}}$ films by $\mathrm{NH}_{3}$ plasma exposure has been previously explored and has been found to degrade passivation. ${ }^{27}$ Contrarily, for U2 and G1, the $S_{\text {eff }}$ is reduced from 50 to $15 \mathrm{~cm} / \mathrm{s}$. This behavior is consistent with the work of Butler et al. ${ }^{11}$ They use molecular dynamics modeling to demonstrate that a $\operatorname{SiN}_{\mathrm{x}}$ gradient induces a reduction of the $K$ - and $N$-center defect concentration at the interface, mitigating the defects' impact on recombination at the c-Si/ $\mathrm{SiN}_{\mathrm{x}}$ interface. In addition, the work of Lamers et al. shows experimentally that a gradient in stoichiometry produced by nitridation of the c-Si, prior to $\mathrm{SiN}_{\mathrm{x}}$ deposition, improves surface passivation. ${ }^{10}$

These films offer potential optical improvements for devices to mitigate (or potentially promote) reflection. ${ }^{5-7}$ The time constant of the change in gas ratio depends on: (1) chamber temperature, (2) chamber volume, (3) total gas flow, (4) pre- and postignition gas ratio, and (5) the relative consumption of the deposition gases. First, we determine the chamber volume by measuring the reactor pressure as a function of moles of gas added. When measured at room temperature, the chamber volume was found to be 22.91 . An effective volume was determined under conditions representative of the depositions procedure (deposition plate temperature $400{ }^{\circ} \mathrm{C}$ and flow rate $40 \mathrm{sscm}$ at a pressure of $650 \mathrm{mTorr})$. By comparing the effective volume with the room-temperature measured volume, we found that the 
temperature of the PECVD gases is $150^{\circ} \mathrm{C}$ during deposition The determination of volume and average gas temperature indicated that at a total gas flow of $40 \mathrm{sscm}$ we are refreshing the reactor gases ever $21 \mathrm{~s}$. The refresh rate is simple proxy for the time constant of the changing gas flow ratio post plasma ignition. We model the molar ratio of $\left[\mathrm{NH}_{3}\right]$ : $\left[\mathrm{SiH}_{4}\right]$, $X_{\text {gas }}$, by considering the mass balance of the system. The change in molar concentration is determined by the rate of moles of ammonia and silane added, less the rate of ammonia and silane removed by the vacuum pump and incorporated in the deposited films. As the process pressure is fixed, the moles of gas added is equivalent to those removed by vacuum and deposition (computed from calibrated deposition rates with density measurements). In other words, the molar concentration of ammonia and silane are solved discretely with the knowledge of the initial concentrations at preignition. We model $X_{\text {gas }}$ for films G1 and G2 and plot it versus the deposition thickness in Fig. 2(b). The deposition time was calibrated to thickness by the uniform samples. The deposition rate was assumed to vary linearly between the rates measured for the uniform films U2 and U3 (as listed in Table I). From the comparison of $X_{\mathrm{RBS}}$ and $n_{633}$, the influence of $X_{\text {gas }}$ is clear. This simple modeling aids in designing recipes for graded films.

The impact of the graded and uniform layers on IBC solar cell efficiency was simulated. The optical losses of the films was estimated using the procedure and software developed by McIntosh et al. ${ }^{13-15}$ The IBC cell modeling was undertaken using the procedure described by Franklin et $a l .{ }^{28} \mathrm{In}$ essence, five random pyramidally textured cells are modeled with different optical and passivation properties represented by the films studied in this work. The graded layers G1 and G2 were modeled by films comprised of five layers, owing to the restrictions of the software. ${ }^{14}$ The graded layer stack thicknesses were scaled for optimal AR properties while maintaining refractive index profiles measured in Fig. 2(a). Each cell's films were optimized to give the highest generation under standard test conditions, with a second coating of $\mathrm{SiO}_{2}$, in line with the $24.4 \%$ efficient cell fabricated and modeled by Franklin et al. ${ }^{28}$ The simulated cell parameters are summarized in Table II. From these comparative simulations, the strongly graded film G2 outperforms the other films, affording the best combination of optics and passivation to achieve a final efficiency (enhancement) of $0.9 \%$ absolute compared to the best uniform film. Further, the

TABLE II. Simulated IBC cell parameters where the cells front surface ARC/ passivating layers are formed by that presented in this work.

\begin{tabular}{lcccccc}
\hline \hline Spl. & $T$ film $(\mathrm{nm})$ & $T \mathrm{SiO}_{2}(\mathrm{~nm})$ & $J_{\mathrm{sc}}\left(\mathrm{mA} / \mathrm{cm}^{2}\right)$ & $V_{\mathrm{oc}}(\mathrm{mV})$ & $F F(\%)$ & $\eta_{\mathrm{IBC}}(\%)$ \\
\hline $\mathrm{U} 1$ & $5^{\mathrm{a}}$ & 108 & 35.3 & 664 & 81.8 & 19.2 \\
$\mathrm{U} 2$ & 63 & 92 & 36.3 & 666 & 81.8 & 19.8 \\
$\mathrm{U} 3$ & $5^{\mathrm{a}}$ & 111 & 40.1 & 705 & 83.0 & 23.5 \\
$\mathrm{G} 1$ & $66^{\mathrm{b}}$ & 93 & 40.5 & 691 & 81.8 & 22.9 \\
$\mathrm{G} 2$ & $65^{\mathrm{b}}$ & 94 & 41.9 & 703 & 82.5 & 24.4 \\
\hline \hline
\end{tabular}

${ }^{\text {a }}$ Thickness constrained to a minimum of $5 \mathrm{~nm}$.

${ }^{\mathrm{b}}$ Combined thickness of the layer stack. surface passivation and optics of G2 is comparable to the exceptionally good properties of the layers produced by Wan et al., ${ }^{2}$ where they achieve excellent passivation with low index, nitrogen-rich films. This behavior is in contrast with the work of Lauinger et al., ${ }^{3}$ which found that passivation improved as the films became more silicon rich. We speculate that the films produced by Wan et al. resulted in a silicon-rich interfacial layer resulting in excellent passivation and optics.

\section{SUMMARY AND CONCLUSIONS}

A new simple single-step method for the deposition of graded $\mathrm{SiN}_{\mathrm{x}}$ films has been demonstrated. The composition and refractive index of the films were verified by RBS-C and $\mathrm{SE}$, respectively, and compared with a simple gas flow model. A strong correlation was found between modeled gas ratio, and the measured RBS N:Si ratio and $n_{633}$. The deposition where the gas ratio was changed from 0 to 3 (film G2) resulted in a measured change in RBS N:Si ratio from 0.2 to 1.15 and in $n_{633}$ from 2.96 to 1.90. Surface passivation of the graded films was compared with that of the uniform films that had the same set gas flows at the time of plasma ignition. Two opposite trends were observed. When the interfacial film was silicon-rich silicon nitride, there was a fourfold reduction in $S_{\text {eff }}$ to $15 \mathrm{~cm} / \mathrm{s}$. Contrarily, when the interfacial film was amorphous silicon, the gradient film passivation was worse but still achieved an $S_{\text {eff }}$ of $4.4 \mathrm{~cm} / \mathrm{s}$. We speculate that the reduction in $S_{\text {eff }}$ is caused by enhanced interface hydrogenation and/or a redistribution of defects in the $\mathrm{SiN}_{\mathrm{x}},{ }^{10,11}$ and the increase in $S_{\text {eff }}$ was owing to nitrogen insertion. ${ }^{27}$ The reported method for graded film deposition relies on the noninstantaneous replacement of deposition gases after plasma ignition and offers a simple, single step approach, which can also be used to enhance the efficiency of other optoelectronic devices currently employing a singlelayer ARC.

\section{ACKNOWLEDGMENTS}

The authors acknowledge the Australian Renewable Energy Agency funding of this work through Grant Nos. 3F006, 3-F020, and 2014/RND008. The authors acknowledge the access to NCRIS facilities (ANFF and the Heavy Ion Accelerator Capability) at the Australian National University. In addition, they thank Andres Cuevas for his advice and helpful discussions on this work.

\footnotetext{
${ }^{1}$ T. Lauinger, J. Schmidt, A. G. Aberle, and R. Hezel, Appl. Phys. Lett. 68, 1232 (1996)

${ }^{2}$ Y. Wan, K. R. McIntosh, A. F. Thomson, and A. Cuevas, IEEE J. Photovoltaics 3, 554 (2013).

${ }^{3}$ T. Lauinger, J. Moschner, A. G. Aberle, and R. Hezel, J. Vac. Sci. Technol. A 16, 530 (1998).

${ }^{4}$ Y. Wan, K. R. McIntosh, and A. F. Thomson, AIP Adv. 3, 032113 (2013).

${ }^{5}$ K.-H. Kim and Q.-H. Park, Sci. Rep. 3, 1 (2013).

${ }^{6}$ A. Mahdjoub and L. Zighed, Thin Solid Films 478, 299 (2005).

${ }^{7}$ S. Chhajed, M. F. Schubert, J. K. Kim, and E. F. Schubert, Appl. Phys. Lett. 93, 251108 (2008).

${ }^{8}$ B. S. Richards, S. F. Rowlands, C. B. Honsberg, and J. E. Cotter, Prog. Photovoltaics 11, 27 (2003).
} 
${ }^{9}$ S. Winderbaum, F. Yun, and O. Reinhold, J. Vac. Sci. Technol. A 15, 1020 (1997).

${ }^{10}$ M. W. Lamers, K. T. Butler, J. H. Harding, and A. Weeber, Sol. Energy Mater. Sol. Cells 106, 17 (2012).

${ }^{11}$ K. T. Butler, M. P. Lamers, A. W. Weeber, and J. H. Harding, J. Appl. Phys. 110, 124905 (2011).

${ }^{12}$ A. Fell, IEEE Trans. Electron Devices 60, 733 (2013).

${ }^{13}$ K. R. McIntosh et al., Quantifying the Optical Losses in Back-Contact Solar Cells (IEEE, Denver, CO, 2014), pp. 0115-0123.

${ }^{14}$ K. McIntosh, "PV Lighthouse," www.pvlighthouse.com.au/, 2015.

${ }^{15}$ K. R. McIntosh and S. C. Baker-Finch, OPAL 2: Rapid Optical Simulation of Silicon Solar Cells (IEEE, Austin TX, 2012), pp. 000265-000271.

${ }^{16}$ W. Kern and D. A. Puotinen, RCA Rev. 31, 187 (1970).

${ }^{17}$ Y. Wan, "Highly transparent highly passivating silicon nitride coatings for solar cells," thesis (The Australian National University, 2014).

${ }^{18}$ J. S. Williams and R. G. Elliman, "Channeling," in Ion Beams for Materials Analysis (Academic, Sydney, 1989), Chap. 6.

${ }^{19}$ L. R. Doolittle, Nucl. Instrum. Methods Phys. Res. Sect. B 9, 344 (1985).
${ }^{20} \mathrm{~W}$. Soppe et al., On Combining Surface and Bulk Passivation of $S_{i N}: H$ Layers for $m c$-Si Solar Cells (IEEE, New Orleans, LA, 2002), pp. 158.

${ }^{21}$ C. Herzinger, B. Johs, W. McGahan, J. Woollam, and W. Paulson, J. Appl. Phys. 83, 3323 (1998).

${ }^{22}$ G. E. Jellison, Jr. and F. A. Modine, Appl. Phys. Lett. 69, 371 (1996).

${ }^{23}$ D. A. G. Bruggeman, Ann. Phys. 416, 636 (1935).

${ }^{24}$ D. E. Kane and R. M. Swanson, Proceedings of the 18th IEEE Photovoltaic Specialists Conference (IEEE, Las Vagas, 1985).

${ }^{25}$ A. Richter, S. W. Glunz, F. Werner, J. Schmidt, and A. Cuevas, Phys. Rev. B 86, 165202 (2012).

${ }^{26}$ H. T. Nguyen, S. C. Baker-Finch, and D. Macdonald, Appl. Phys. Lett. 104, 112105 (2014).

${ }^{27}$ Y. Wan, K. R. McIntosh, A. F. Thomson, and A. Cuevas, Appl. Phys. Lett. 106, 041607 (2015).

${ }^{28}$ E. Franklin et al., "Design, fabrication and characterisation of a $24.4 \%$ efficient interdigitated back contact solar cell," Prog. Photovoltaics (published online 2014). 